\title{
Resistensi lalat rumah, Musca domestica Linnaeus (Diptera: Muscidae) dari empat kota di Indonesia terhadap permetrin dan propoksur
}

\author{
Resistence of house flies, Musca domestica Linnaeus (Diptera: \\ Muscidae) of four cities in Indonesia to permethrin and propoxur \\ Intan Ahmad ${ }^{*}$, Silvi Susanti², Kustiati' ${ }^{1}$, Sri Yusmalinar', Resti Rahayu', \\ Nova Hariani ${ }^{4}$
}

\author{
${ }^{1}$ Sekolah Ilmu dan Teknologi Hayati, Institut Teknologi Bandung \\ Jalan Ganesa 10, Bandung 40132 \\ ${ }^{2}$ Program Studi Pendidikan Biologi STKIP PGRI Sumatera Barat \\ Jalan Gunung Pangilun, Padang 25111 \\ ${ }^{3}$ Jurusan Biologi, FMIPA, Universitas Andalas \\ Kampus Unand Limau Manis, Padang 25163 \\ ${ }^{4}$ Jurusan Biologi, FMIPA, Universitas Mulawarman \\ Jalan Barong Tongkok No.04, Gunung Kelua Samarinda 75123
}

(diterima Oktober 2014, disetujui Juni 2015)

\begin{abstract}
ABSTRAK
Lalat rumah (Musca domestica Linnaeus) merupakan hama permukiman yang menimbulkan masalah kesehatan, ekonomi dan estetika. Walau pengendalian secara intensif dengan menggunakan insektisida sudah dilakukan, terjadinya kegagalan pengendalian yang kemungkinan disebabkan oleh terjadinya resistensi lalat terhadap insektisida masih dilaporkan. Uji hayati terhadap M. domestica yang dikoleksi dari kota Jakarta (JKT), Bandung (BDG), Yogyakarta (YGY) dan Surabaya (SBY) dengan metoda topikal dilakukan untuk mengetahui status dan mekanisme resistensi lalat rumah terhadap insektisida piretroid (permetrin) dan karbamat (propoksur). Hasil penelitian menunjukkan bahwa dibandingkan dengan strain yang paling rentan YGY, strain BDG adalah strain yang paling resisten terhadap permetrin dengan rasio resistensi $90 \%\left(\mathrm{RR}_{90}\right)$ adalah 133,7 kali, sedangkan strain SBY adalah strain yang paling resisten terhadap propoksur dengan $\mathrm{RR}_{90} 38,36$ kali, diikuti oleh BDG dengan $\mathrm{RR}_{90}$ 18,22 kali. Penambahan piperonil butoksida (PBO) pada permetrin dan propoksur pada hampir semua strain menurunkan nilai $\mathrm{LD}_{50}$ dan meningkatkan rasio sinergis (SR) yang mengindikasikan bahwa enzim oksidasi fungsi campur (mixed function oxidase) berperan penting dalam pengembangan resistensi lalat terhadap permetrin dan propoksur. Hasil penelitian ini merupakan laporan pertama dari Indonesia tentang adanya resistensi lalat rumah terhadap insektisida permetrin dan propoksur.
\end{abstract}

Kata kunci: hama permukiman, $\mathrm{LD}_{50}$, $\mathrm{MFO}$, sinergis, toksisitas

\begin{abstract}
House flies (Musca domestica Linnaeus) is one of the common urban pests causing health, economics, and aesthetics problems. Although intensive control by using inseticides are carried out, there are reports of control failures, which are probably due to insect resistance. Bioassay tests with topical application to study the status as well as resistance mechanism of house flies collected from the city of Jakarta (JKT), Bandung (BDG), Yogyakarta (YGY) and Surabaya (SBY) to pyrethroid (permethrin) and carbamate (propoxur) insecticides were carried out. The results show that, as compared to the most susceptible strain (YGY), we found that BDG strain is highly resistant to permethrin with resistance ratio (RR) of 133.7 fold. SBY strain was the most resistant to
\end{abstract}

\footnotetext{
*Penulis Korespondensi: Intan Ahmad. Sekolah Ilmu dan Teknologi Hayati, Institut Teknologi Bandung, Jalan Ganesa 10, Bandung 40132 Tel: 022-2511575, Faks: 022-2515033, Email: intan@itb.ac.id
} 
propoxur with RR of 38.36 fold, followed by Bandung strain with RR of 18.22 fold. The addition of piperonyl butoxide (PBO) to either permethrin or propoxur in most of the strains caused a decrease in $\mathrm{LD}_{50}$ values and increasing the synergist ratio (SR) suggesting that the detoxifying enzyme mixed function oxidase (MFO) played an important role in the development of resistance to permethrin and propoxur. Our study is the first report of $M$. domestica resistance to permethrin and propoxur in Indonesia.

Key words: $\mathrm{LD}_{50}, \mathrm{MFO}$, synergist, toxicity, urban pest

\section{PENDAHULUAN}

Lalat rumah, Musca domestica Linnaeus, merupakan hama yang sering ditemui di sekitar permukiman penduduk, peternakan maupun industri makanan. Selain itu, serangga ini juga dikenal sebagai vektor mekanik berbagai penyakit yang berbahaya bagi kesehatan manusia, seperti kolera, tifus, diare, dan disentri. Untuk mengendalikan hama ini, berbagai upaya telah dilakukan, seperti tindakan sanitasi lingkungan agar lalat tidak dapat berkembang biak. Selain itu, bila pengendalian ingin dilakukan secara cepat, insektisida banyak digunakan, tetapi penggunaannya sering tidak sesuai dengan prinsip pengendalian hama terpadu. Diperparah dengan tingginya populasi yang harus dikendalikan, serta siklus hidup lalat rumah yang pendek, penggunaan insektisida tersebut telah mempercepat terjadinya resistensi lalat rumah terhadap berbagai golongan insektisida. Terjadinya resistensi lalat terhadap berbagai insektisida adalah hal yang umum terjadi dan telah dilaporkan dari berbagai negara di dunia (Kaufman et al. 2010; Akiner \& Caglar 2006).

Walaupun demikian, untuk Indonesia belum ada laporan tentang status resistensi lalat rumah terhadap insektisida yang biasa digunakan untuk mengendalikannya. Data mengenai status resistensi lalat rumah terhadap insektisida serta mekanisme resistensi yang ada dapat digunakan untuk mengembangkan metode pengendalian yang lebih baik, termasuk agar insektsida dapat digunakan untuk waktu yang lebih lama, seperti yang telah diterapkan oleh beberapa negara maju, seperti Denmark. Pendataan resistensi perlu dilakukan untuk mendeteksi sedini mungkin adanya individu resisten dalam populasi dan mengetahui tingkat dan mekanisme resistensi yang terjadi.

Penelitian mengenai status resistensi serangga permukiman di Indonesia terhadap insektisida baru dilaporkan pada nyamuk Aedes aegypti Linnaeus (Astari \& Ahmad 2005; Ahmad et al. 2006; 2007) dan kecoa Blattella germanica (Linnaeus) (Ahmad et al. 2008; Rahayu et al. 2012).

Dengan latar belakang di atas, penelitian ini dilakukan untuk mengetahui status resistensi lalat rumah terhadap insektisida yang biasa digunakan di Indonesia, yaitu permetrin dari golongan piretroid dan propoksur dari golongan karbamat, termasuk melihat mekanisme resistensi yang terjadi dengan mempergunakan piperonil butoksida (PBO) sebagai sinergis pada lalat rumah yang dikoleksi dari empat kota besar di Indonesia, yaitu Jakarta, Bandung, Yogyakarta, dan Surabaya. PBO adalah sinergis insektisida yang biasa digunakan untuk mengatasi terjadinya resistensi pada insektisida piretroid yang bekerja dengan cara menghambat aktivitas enzim detoksifikasi, seperti enzim oksidasi fungsi campur mixed function oxidase (MFO). Walaupun demikian, penambahan sinergis, seperti PBO hanya akan efektif bila resistensi yang terjadi adalah karena mekanisme biokimia yang melibatkan enzim detoksifikasi (Martin et al. 1997).

\section{BAHAN DAN METODE}

\section{Tempat dan waktu penelitian}

Penelitian dilakukan di Laboratorium Entomologi, Sekolah Ilmu dan Teknologi Hayati, Institut Teknologi Bandung, dengan menggunakan strain lalat rumah yang dikoleksi pada akhir tahun 2010 dari empat kota besar di Indonesia, yaitu Jakarta (JKT), Bandung (BDG), Yogyakarta (YGY), dan Surabaya (SBY).

\section{Pemeliharaan dan perbanyakan lalat rumah}

Lalat rumah dipelihara dalam kotak kasa berukuran $30 \mathrm{~cm}$ × $30 \mathrm{~cm}$ × $30 \mathrm{~cm}$ pada suhu ruangan dan fotoperioda $12: 12$ mengacu pada metode Schoof (1964). Setiap populasi disediakan hati sapi dalam cawan petri sebagai media bagi perkembangan lalat rumah meletakkan telur. 
Pakan imago terdiri atas campuran susu bubuk, ragi, dan gula. Setelah 24 jam, hati sapi yang telah mengandung telur lalat rumah dipindahkan ke medium larva hingga menjadi pupa. Pupa dipelihara dalam kurungan terpisah hingga muncul menjadi imago lalat rumah yang selanjutnya digunakan sebagai lalat percobaan.

\section{Pengujian resistensi lalat rumah terhadap permetrin dan propoksur di lapangan}

Insektisida yang digunakan adalah permetrin 94\% (PT Triman Sentosa Jakarta) dan propoksur 92,25\% (PT Everspring Jakarta). Untuk mendeteksi mekanisme resistensi digunakan PBO (PT Gelpi Kurnia Lestari) dan sebagai pelarut digunakan aceton pro analisis (Merck). Sepuluh lalat rumah betina dimasukkan dalam toples berdiameter $12 \mathrm{~cm}$, tinggi $11,5 \mathrm{~cm}$, dan prosedur ini diulang lima kali. Sebelum perlakuan, lalat rumah dipingsankan dengan menaruhnya dalam refrigerator selama tiga menit. Insektisida dengan berbagai konsentrasi, yang telah dilarutkan dalam aseton, diteteskan pada bagian dorsal toraks untuk menentukan dosis kematian dari insektisda uji terhadap populasi lalat rumah (Kristensen \& Jespersen 2007a,b).

Serial dosis yang digunakan dalam studi ini adalah 4-5 dosis dengan mortalitas berkisar antara 5\% dan 95\% untuk setiap insekstisida uji dan strain lalat rumah. Prosedur diulang lima kali. Setelah aplikasi, lalat rumah diletakkan dalam toples bersih dan diberi makan larutan sukrosa $10 \%$. Jumlah yang mati dicatat pada 48 jam setelah perlakuan. Lalat rumah dianggap mati jika tidak bergerak ketika disentuh.

Prosedur yang sama juga digunakan untuk studi sinergisme, dengan 1 mikroliter larutan insektisida dan PBO (1:5) diaplikasikan pada abdomen (Kristensen et al. 2001).

\section{Analisis data}

Tingkat resistensi dianalisis dari dosis kematian $50 \%\left(\mathrm{LD}_{50}\right)$ dan $90 \%\left(\mathrm{LD}_{50}\right)$ yang diperoleh dari analisis probit POLO-PC (Le Ora Software 2004). Rasio resistensi $\left(\mathrm{RR}_{50}\right.$ dan $\left.\mathrm{RR}_{90}\right)$ dihitung dengan membandingkan $\mathrm{LD}_{50}$ atau $\mathrm{LD}_{90}$ strain uji dengan $\mathrm{LD}_{50}$ atau $\mathrm{LD}_{90}$ strain rentan. Berdasarkan penelitian awal, strain YGY ditetapkan sebagai strain rentan pembanding. Rasio sinergis (SR) dihitung dengan membandingkan rasio resistensi (RR) tanpa PBO dengan RR dengan PBO (Cochran 1994). Nilai SR $>1$ menunjukkan adanya efek sinergis dari PBO terhadap insektisida dalam strain tertentu, yang berarti bahwa penambahan PBO memberikan efek positif dengan menurunkan $\mathrm{LD}_{50}$. Perbedaan signifikan antara RR dan RS menunjukkan adanya aktivitas enzim detoksifikasi sebagai salah satu mekanisme resistensi terhadap insektisida yang dikembangkan oleh lalat rumah.

\section{HASIL}

\section{Toksisitas permetrin terhadap lalat rumah populasi lapangan}

Toksisitas permetrin ditentukan dari empat populasi lapangan lalat rumah yang dikoleksi. Nilai $\mathrm{LD}_{90}$ berkisar antara $1,71 \times 10^{-3}$ hingga $228,70 \times 10^{-3} \mu \mathrm{g} /$ individu pada 48 jam setelah perlakuan (Tabel 1). Nilai slope dari kurva respons dosis (garis probit) bervariasi antara 1,398 $\pm 0,339$ hingga 2,259 $\pm 0,253$. Rasio resistensi ditentukan dengan membandingkan dengan nilai $\mathrm{LD}_{90}$ suatu strain terhadap nilai $\mathrm{LD}_{90}$ terendah dari strain YGY yang dianggap masih rentan. Berdasarkan perhitungan ini diperoleh nilai $\mathrm{RR}_{90}$ berkisar 3,85133,70 kali dibandingkan dengan strain YGY.

\section{Toksisitas propoksur terhadap lalat rumah populasi lapangan}

Toksisitas $\left(\mathrm{LD}_{90}\right)$ propoksur terhadap empat populasi lalat rumah berkisar antara 1,636 dan $62,771 \mu \mathrm{g} /$ individu yang membuat $\mathrm{RR}_{90} 7,29$ 38,36, 13 kali dibandingkan dengan strain paling rentan, yaitu YGY (Tabel 2). Nilai slope terhadap

Tabel 1. Tingkat resistensi Musca domestica terhadap permetrin

\begin{tabular}{lccccrc}
\hline Strain & $\mathrm{N}$ & $\begin{array}{c}\mathrm{LD}_{50}\left(\mathrm{x} 10^{-3}\right) \mu \mathrm{g} / \\
\text { Individu }\end{array}$ & $\mathrm{RR}_{50}$ & $\begin{array}{c}\mathrm{LD}_{90}\left(\mathrm{x} 10^{-3}\right) \mu \mathrm{g} / \\
\text { Individu }\end{array}$ & $\mathrm{RR}_{90}$ & Slope $\pm \mathrm{SD}$ \\
\hline YGY & 304 & 0,46 & 1,00 & 1,71 & 1,00 & $2,259 \pm 0,253$ \\
BDG & 300 & 2,77 & 6,02 & 228,70 & 133,70 & $1,398 \pm 0,339$ \\
JKT & 295 & 1,29 & 2,80 & 8,47 & 4,95 & $1,567 \pm 0,216$ \\
SBY & 297 & 1,76 & 3,82 & 6,58 & 3,85 & $2,242 \pm 0,276$ \\
\hline
\end{tabular}


propoksur berkisar dari $0,893 \pm 0,223$ hingga 1,630 $\pm 0,262$, dan untuk semua strain nilainya kurang dari dua yang menunjukkan bahwa respons dari strain-strain tersebut terhadap aplikasi propoksur sangat heterogen.

\section{Sinergisme aktivitas permetrin dan propoksur pada lalat rumah}

Pemberian permetrin dan $\mathrm{PBO}$ pada strain YGY, BDG, JKT dan SBY semuanya menunjukkan efek sinergis masing-masing dengan rasio sinergis 2,03, 184,43, 1,66, dan 3,17. Potensi sinergistik tampak tinggi sekali pada strain Bandung $(\mathrm{SR}=$ 184,43) (Tabel 3).

Hal serupa juga terjadi pada propoksur, penambahan $\mathrm{PBO}$ menunjukkan efek sinergisme pada strain YGY, BDG, dan JKT, masing-masing dengan SR 13,81, 30,82, dan 35,37. Pada strain SBY, penambahan PBO tidak memberikan dampak sinergis karena tidak ada kematian lalat uji (Tabel 3).

\section{PEMBAHASAN}

Hasil penelitian menunjukkan bahwa semua strain lalat rumah yang dikoleksi dari Jakarta, Bandung dan Surabaya telah resisten terhadap dua kelompok insektisida yang umum digunakan di Indonesia, yaitu permetrin (piretroid) dan propoksur (karbamat) jika dibandingkan dengan strain yang paling rentan (strain YGY). Walaupun demikian berdasarkan klasifikasi resistensi Lee et al. (1996) yang telah dimodifikasi oleh Rahayu et al. (2012), kecuali untuk strain Bandung yang mempunyai rasio resistensi amat tinggi $(133,70)$, tampaknya tingkat resistensi lalat rumah dari JKT dan SBY masih rendah terhadap permetrin, yaitu masing masing 3,85 dan 4,95 kali. Resistensi terhadap propoksur secara umum cukup tinggi, yaitu 7,29-38,36 kali. Menarik untuk dicatat di sini bahwa hasil penelitian ini mirip dengan hasil penelitian yang dilakukan oleh Bong \& Zairi (2010) di Penang Malaysia, yang secara

Tabel 2. Tingkat resistensi Musca domestica terhadap propoksur

\begin{tabular}{lccrrrr}
\hline Strain & $\mathrm{N}$ & $\begin{array}{c}\mathrm{LD}_{50}\left(\mathrm{x} 10^{-3}\right) \mu \mathrm{g} / \\
\text { Individu }\end{array}$ & $\mathrm{RR}_{50}$ & $\begin{array}{c}\mathrm{LD}_{90}\left(\mathrm{x} 10^{-3}\right) \mu \mathrm{g} / \\
\text { Individu }\end{array}$ & $\mathrm{RR}_{90}$ & Slope $\pm \mathrm{SD}$ \\
\hline YGY & 299 & 60,13 & 1,00 & 1636,27 & 1,00 & $0,893 \pm 0,223$ \\
BDG & 292 & 3194,60 & 53,13 & 29821,00 & 18,22 & $1,321 \pm 0,246$ \\
JKT & 311 & 1952,85 & 32.48 & 11937,74 & 7,29 & $1,630 \pm 0,262$ \\
SBY & 300 & 2969,86 & 49.39 & 62771,00 & 38,36 & $0,931 \pm 0,196$ \\
\hline
\end{tabular}

Tabel 3. Sinergisme aktivitas permetrin dan propoksur pada LD90 Musca domestica populasi lapangan

\begin{tabular}{llccc}
\hline Strain & \multicolumn{1}{c}{ Perlakuan } & $\mathrm{N}$ & $\begin{array}{c}\mathrm{LD}_{90}\left(\mathrm{x} 10^{-3}\right) \\
\mu \mathrm{g} / \text { individu }\end{array}$ & Rasio sinergis (SR) \\
\hline YGY & Permetrin & 304 & 1,71 & - \\
& Permetrin + PBO & 249 & 0,84 & - \\
& Propoksur & 299 & 1636,27 & 13,81 \\
& Propoksur + PBO & 250 & 118,42 & - \\
BDG & Permetrin & 300 & 228,70 & 184,43 \\
& Permetrin + PBO & 252 & 1,24 & - \\
& Propoksur & 292 & 29821,00 & 30,82 \\
& Propoksur + PBO & 244 & 967,60 & - \\
JKT & Permetrin & 295 & 8,47 & - \\
& Permetrin + PBO & 255 & 5,10 & 35,37 \\
& Propoksur & 311 & 11937,74 & - \\
& Propoksur + PBO & 249 & 337,51 & 3,17 \\
\hline
\end{tabular}


umum menunjukkan bahwa lalat rumah masih rentan terhadap permetrin, tetapi menunjukkan resistensi yang amat tinggi terhadap propoksur, masing-masing dengan resistensi rasio (RR) 0,501,96 dan 10,28-99,00. Lebih lanjut disebutkan bahwa tingginya resistensi terhadap propoksur diperkirakan karena terjadinya resistensi silang dengan insektisida dari kelompok organofostat yang digunakan untuk mengendalikan lalat di area peternakan (Bong \& Zairi 2010). Hal yang sama mungkin juga terjadi di Indonesia, walau penggunaan propoksur sebagai bahan aktif untuk mengendalikan lalat rumah amat sedikit digunakan, jika dibandingkan dengan kelompok piretroid. Di Indonesia beberapa insektisida aerosol yang didaftarkan untuk mengendalikan nyamuk, kecoa, dan lalat rumah, bahan aktifnya terdiri atas kombinasi propoksur (karbamat) dan transflutrin (piretroid) (Rahayu et al. 2012).

Data dari penelitian ini juga menunjukkan bahwa strain Bandung (BDG) telah mengembangkan resistensi terhadap permetrin dan propoksur, sementara strain SBY hanya resisten terhadap propoksur saja dan strain YGY masih sangat rentan untuk kedua tipe insektisida (hal ini menjadi alasan YGY dijadikan sebagai strain pembanding), walaupun hasil penelitian yang dilaporkan dalam penelitian ini tidak menggunakan strain rentan $M$. domestica standar yang belum pernah terpapar insektisida, sebagai pembanding. Hasil penelitian kami yang terbaru (Kustiati et al. 2016) di ITB menunjukkan bahwa 26 dari 32 strain M. domestica yang dikoleksi dari seluruh Indonesia, termasuk daerah yang dikoleksi yang dilaporkan dalam penelitian ini (JKT, BDG, YGY, dan SBY), menunjukkan tingkat resistensi yang tinggi sekali terhadap permetrin dengan rasio resistensi $\left(\mathrm{RR}_{50}\right)$ berkisar antara 190-25192 kali.

Tiga nilai slope dari BDG dan JKT kurang dari dua, yang menunjukkan bahwa kedua strain tersebut memberikan respon heterogen terhadap insektisida permetrin. Strain SBY dan YGY menunjukkan nilai slope lebih dari dua yang menunjukkan bahwa strain tersebut memberikan respon homogen terhadap permetrin. Seperti disampaikan oleh Servin-Villagas et al. (2006), homogenitas pada populasi dapat dilihat dari nilai slope, yang juga berhubungan dengan tingkat resistensi terhadap insektisida. Hasil penelitian ini menunjukkan bahwa strain BDG dan JKT tersusun oleh individu-individu yang berbeda kerentanan dan resistensinya terhadap permetrin dibandingkan dengan strain lain (ditunjukkan oleh nilai $\mathrm{RR}_{50}$ dan $\mathrm{RR}_{90}$ pada strain BDG).

Pada strain BDG, penambahan PBO amat mengurangi nilai LD, dengan SR sebesar 184,43 yang mengindikasikan bahwa resistensi yang tinggi pada strain Bandung (133,7 kali) terhadap permetrin, kemungkinan besar melibatkan aktivitas MFO, walau diduga terdapat mekanisme lain yang juga ikut terlibat (Astari \& Ahmad 2005). Hal ini mungkin juga berlaku untuk semua strain, baik yang diberi perlakuan dengan permetrin maupun propoksur yang ditambah dengan PBO. Hal ini juga dapat dijadikan alasan bahwa penggunaan PBO dapat meningkatkan toksisitas permetrin dan propoksur sekaligus memperpanjang masa pakai insektisida yang penting dalam strategi pengendalian hama secara terpadu. Walaupun demikian, khusus untuk strain SBY, strain yang paling resisten terhadap propoksur (RR 38,36 kali) (Tabel 2), pemberian PBO ternyata tidak meningkatkan toksisitas propoksur, seperti terjadi pada strain lainnya, tetapi justru mengakibatkan propoksur tidak efektif karena tidak ada lalat yang mati. Hal ini kemungkinan dapat terjadi, seperti yang dilaporkan oleh Sanchez-Arroyo et al. (2001) pada Blattella germanica (Linnaeus) bahwa walaupun tidak umum dan hanya untuk strain tertentu, penetrasi propoksur secara kutikular berkurang dengan adanya PBO.

\section{KESIMPULAN}

Tingkat resistensi lalat rumah pada populasi lapangan dari empat kota besar di Indonesia berbeda-beda, yaitu rendah terhadap permetrin dan sedang sampai tinggi terhadap propoksur. Secara umum penambahan PBO sebagai sinergis menurunkan nilai dosis letal, yang mengindikasikan MFO berperan dalam terjadinya resistensi terhadap permetrin dan propoksur.

\section{UCAPAN TERIMA KASIH}

Penelitian ini sebagian didanai oleh Osaka Gas Foundation dan PEI Bandung-SITH. Penulis mengucapkan terima kasih kepada PT Triman 
Sentosa Jakarta, PT Everspring Jakarta dan PT Gelpi Kurnia Lestari atas ketersediaan insektisida dan sinergis yang digunakan dalam penelitian.

\section{DAFTAR PUSTAKA}

Ahmad I, Astari S, Rahardjo B, Tan M, Munif A. 2006. Resistance of Aedes aegypti from three province in Indonesia to pyrethroid and organophosphate insecticides. In: International Conference on Mathematics and Natural Science (ICMNS), (Bandung, 29-30 November 2006). Bandung: Institut Teknologi Bandung.

Ahmad I, Astari S, Tan M. 2007. Resistance of Aedes aegypti (Diptera: Culicidae) in 2006 to pyrethroid insecticides in Indonesia and its association with oxidase and esterase levels. Pakistan Journal of Biological Science 10:3688-3692. doi http:// dx.doi.org/10.3923/pjbs.2007.3688.3692.

Ahmad I, Sriwahyuningsih, Astari S, Putra RE, Permana AD. 2008. Monitoring pyrethroid resistance in field collected Blattella germanica Linn. (Dictyoptera: Blattellidae) in Indonesia. Entomological Research 39:114-118. doi: http:// dx.doi.org/10.1111/j.1748-5967.2009.00205.x.

Akiner MM, Caglar SS. 2006. The status and seasonal changes of organophosphate and pyrethroid resistance in Turkish populations of the house fly, Musca domestica L. (Diptera: Muscidae). Journal of Vector Ecology 31:427-433. doi: http://dx.doi.org/10.3376/1081-1710(2006)31 [426:TSASCO]2.0.CO;2.

Astari S, Ahmad I. 2005. Insecticide resistance and effect of piperonyl butoxide as synergist in three strains of Aedes aegypti (Linn.) (Diptera: Culicidae) to insecticide permethrin, cypermethrin, and d-Allethrin. Bulletin of Health Studies 33:73-79.

Bong LJ, Zairi J. 2010. Temporal fluctuations of insecticides resistance in Musca domestica Linn (Diptera; Muscidae) in Malaysia. Tropical Biomedicine 27:317-325.

Cochran DG. 1994. Effect of three synergists on pyrethroid resistance in the German cockroach (Dictyoptera: Blattellidae). Journal of Economic Entomology 87:879-884. doi: http://dx.doi.org/ 10.1093/jee/87.4.879.

Kaufman PE, Nunez ES, Geden CJ, Scharf M. 2010. Selection for resistance to imidacloprid in the house fly (Diptera: Muscidae). Journal of Economic Entomology 103:1937-1942. doi: http://dx.doi.org/10.1603/EC10165.
Kristensen M, Spencer AG, Jespersen JB. 2001. The status and development of insecticide resistance in Danish population of the housefly Musca domestica L. Pest Management Science 57:8289. doi: http://dx.doi.org/10.1002/1526-4998 (200101) 57:1<82::AID-PS251>3.0.CO;2-8.

Kristensen M, Jespersen JB. 2007a. Susceptibility of spinosad in Musca domestica (Diptera: Muscidae) field populations. Journal of Economic Entomology 97:1042-1048. doi: http://dx.doi.org/10.1093/jee/97.3.1042.

Kristensen M, Jespersen JB. 2007b. Susceptibility to thiamethoxam of Musca domestica from Danish livestock farms. Pest Management Science 64:126-32.

Kustiati, Tan MI, Yusmalinar S, Ambarningrum TB, Ahmad I. 2016. Monitoring permethrin and imidacloprid resistance in Indonesian house fly Musca domestica L. (Diptera: Muscidae). In press. Journal of Entomology.

Lee CY, Yap HH, Chong NL. 1996. Insecticide resistance and synergysm in field collection German cockroach (Dictyoptera: Blattellidae) Peninsular Malaysia. Bulletin of Entomological Research 86:675-682. doi: http://dx.doi.org/10. 1017/S0007485300039195.

Martin SH, Ottea JA, Leonard BR, Graves JB, Burris E, Micinski S, Church GE. 1997. Effects of selected synergists on insecticide toxicity in tobacco budworm (Lepidoptera: Noctuidae) in laboratory and field studies. Journal of Economic Entomology 90:723-731. doi: http://dx.doi.org/ 10.1093/jee/90.3.723.

Rahayu R, Ahmad I, Ratna ES, Tan MI, Hariani N. 2012. present status for carbamate, pyrethroids and phenylpyrazole insecticide resistance to German cockroach, Blattella germanica in Indonesia. Journal of Entomology 9:361-367. doi: http://dx.doi.org/10.3923/je.2012.361.367.

Sanchez-Arroyo H, Koehler PG, Valles SM. 2001. Effects of the synergists piperonyl butoxide and s,s,s-tributyl phosphorotrithioate on propoxur pharmacokinetics in Blattella germanica (Blattodea: Blattellidae). Journal of Economic Entomology 94:1209-1216.

Schoof HF. 1964. Laboratory culture of Musca, Fannia and Stomoxys. Bulletin World Health Organiz 31:539-544. doi: http://dx.doi.org/10. 1603/0022-0493-94.5.1209.

Servin-Villegas R, Garcia-Hernandes JL, MuriloAmador B, Tejas A, Martinez-Carillo JL. 2006. Stability of insecticides resistance of silverleaf whitefly (Homoptera: Aleyrodidae) in the absence of selection pressure. Folia Entomológica Mexicana 45:27-34. 